\title{
Q Ensino da Geografia Política Local na Escola como Perspectiva de Efetivação da Cidadania
}

\section{The Teaching of Local Political Geography in the School as Perspective of Effec- tuation of Citizenship}

Lara Moraes Borowski*

Antonio Angelo Martins da Fonseca **

\begin{abstract}
Resumo:
A partir da geografia política é possível trabalhar conteúdos conceituais e atitudinais fundamentais para a efetivação da cidadania, objetivo primaz da educação básica. E a escala local, especificamente, apresenta importantes revelações que são muito bem representadas pelo papel do município no federalismo brasileiro. Com base nestas considerações, objetiva-se neste artigo analisar como se apresentam algumas das abordagens referentes à geografia política presentes na educação básica e discutir sobre a potencialidade da escala local como uma perspectiva de aprendizagem significativa e de efetivação da cidadania. Por fim, é apresentada uma proposta de sequência didática, flexível, que pode ser operacionalizada em sala de aula tomando o município como escala de referência para análise.
\end{abstract}

\section{Abstract:}

From political geography it's possible work fundamentals insights for effective citizenship, primate objective of basic education. And the local scale, specifically, shows important revelations that are very well represented by the county's role on Brazilian federalism. Based on these considerations, the objective of this article is analyze which are the main approaches regarding political geography present in basic education. A proposal of a following didactic, flexible, that could be operated in the classroom taking the city as scale reference for review.
* Bacharel e licenciada em Geografia pela Universidade Federal da Bahia/UFBA e Professora da Rede Municipal de Educação de Camaçari-BA.

** Professor Adjunto do Departamento e do Programa de Pós-Graduação em Geografia da Universidade Federal da Bahia/UFBA.
Palavras-chave:

Geografia Politica, Município, Ensino,

Cidadania

Key-Words:

Political Geography, County,

Teaching, Citizenship. 


\section{INTRODUÇÃO}

T oda e qualquer análise que se debruce sobre o ensino de geografia, independente do enfoque teórico-metodológico que assuma, situa-se na área de interface entre dois campos disciplinares que tem muito a dialogar, a geografia e a educação. Quando analisamos esta relação estamos falando de um processo de transposição didática comum a todos os ramos do conhecimento que geram tanto um saber científico, quanto um saber escolar. Este conceito de transposição didática proposto por Chevallard (1991) nos traz a necessidade de olhar para a relação ensino-aprendizagem colocando no centro do debate a especificidade do conhecimento escolar. O conhecimento acadêmico se transforma ao ser inserido na sala de aula e isso significa, em última instância, adaptação de conceitos e formulações.

Neste artigo são discutidas algumas das abordagens referentes ao ensino de geografia política na educação básica, com base em trabalho de campo e na análise de livros didáticos. Como proposição, são apresentados também caminhos possíveis de transposições didáticas voltadas para uma aprendizagem significativa a partir da realidade política local. Essa discussão chega em boa hora, sobretudo pelo significativo revigoramento que a geografia política em geral, e a brasileira em particular, vem experimentando nos últimos anos. Só no Brasil ocorreram, nos últimos cinco anos, quatro importantes eventos da geografia política: I Simpósio Nacional de Geografia Política que ocorreu em Curitiba em 2009, o II Simpósio Nacional de Geografia Política que ocorreu em Foz do Iguaçu em 2011, o III Simpósio Nacional de Geografia Política que ocorreu em Manaus em 2013, o I Congresso Brasileiro de Geografia Política, Geopolítica e Gestão Territorial - I CONGEO - realizado no Rio de Janeiro em outubro de 2014 e o II Congresso Brasileiro de Geografia Política, Geopolítica e Gestão Territorial - II CONGEO, que será realizado na cidade de Natal em 2016. Ressalta-se, também, a Rede Brasileira de Geografia Política - REBRAGEO, criada a partir do encontro de Manaus em 2013. Mesmo assim, a relação entre geografia política, educação básica e experiências em sala de aula ainda são pouco frequentes nas discussões destes eventos.

Acreditamos que a relevância deste artigo está no tratamento dado a esta relação e nas possíveis contribuições geradas para a ampliação da agenda de discussões que envolvem esta disciplina. Para isso, o presente artigo apresenta dois objetivos gerais. Em um primeiro momento o objetivo central é realizar um diagnóstico relativo à geografia política e sua dimensão local, bem como sobre sua inserção nas salas de aula. São abordadas, inicialmente, questões mais gerais relativas à geografia política e ao ensino da disciplina. Em seguida é realizada uma análise dos Parâmetros Curriculares Nacionais (PCN) e como a dimensão local é abordada no documento em questão. Para balizar de forma mais complexa o diagnóstico pretendido foram analisados os resultados de entrevistas com professores da rede estadual de ensino, em Salvador-BA. O segundo objetivo pretendido neste trabalho é, a partir do diagnóstico realizado, empreender proposições para o ensino da geografia política em sua dimensão local. Para isso são destacados alguns pressupostos teóricos acerca da cidadania e da escala local e em seguida é sistematizada uma proposta de sequência didática envolvendo as referidas questões.

\section{GEOGRAFIA POLÍTICA, ENSINO E RENO- VAÇÃO}

Alguns dos elementos iniciais importantes para o debate situam-se no processo de crise e renovação da geografia brasileira, que encontrou diferentes entraves para ganhar força nos espaços escolares, sendo um dos principais a substituição de história e geografia pela disciplina estudos sociais, em 1971. Foi também neste período que a metodologia dos círculos concêntricos ganhou força. Tal metodologia consiste na idéia de que a ordem dos conteúdos deve seguir as etapas do desenvolvimento psicológico do aluno e, por isso, deve ir do concreto ao abstrato e do local ao global. Neste sentido as escalas geográficas iam sendo hierarquizadas, afirmando-se implicitamente ser a escala local mais simplificada e a global mais complexa. A ideia dos círculos concêntricos perdurou mesmo após a reorganização do currículo, fato que só ocorreu em 1997 com a publicação dos Parâmetros Curriculares Nacionais (PCN). Estes entraves fizeram com que o movimento de renovação da geografia brasileira conquistasse maior espaço na educação básica somente a partir da década de 1980, através do contexto de redemocratização no país. Entretanto, sobre o assunto, Kaercher (2002) afirma que a geografia crítica produzida neste período não chegou a ser, de fato, incorporada na educação básica por que apesar dos conteúdos terem sido renovados houve, de forma geral, uma continuidade dos velhos métodos de ensino. Prevaleceu uma pedagogia tradicional, nos moldes da educação bancária de que nos falou Paulo Freire, embora com conteúdo renovado. Essa situação, entretanto, não ocorreu de forma homogênea, 
pois iniciativas de cunho mais progressistas certamente ocorreram, a depender de cada contexto, instituição de ensino e de cada profissional.

Se, por um lado, a geografia acadêmica brasileira passava por este processo de renovação, por outro também já se fazia presente uma ampla discussão sobre os paradigmas pedagógicos vigentes e outros tantos que poderiam representar uma pedagogia mais crítica. A aprendizagem significativa, por exemplo, surge neste contexto como base na psicologia educacional de Ausubel; Novak; Hanesian (1980), que tem como pressuposto central a aceitação de que o fator isolado mais importante que influencia a aprendizagem é aquilo que o aprendiz já sabe. Podemos afirmar, no entanto, que a preocupação com a aprendizagem significativa, embora não utilizando a referida expressão, também aparece nas obras do sócio-interacionismo de Lev Vygotsky e na perspectiva libertadora de Paulo Freire.

Além do processo de renovação da geografia brasileira, a reformulação das políticas educacionais pós 1988 também deram forma a geografia escolar que se faz hoje. Neste aspecto vale destacar a promulgação da Lei de Diretrizes e Bases da Educação Nacional (LDB) de 1996 e a publicação dos Parâmetros Curriculares Nacionais (PCN), no mesmo período. Sobre os parâmetros, inúmeras foram as críticas a eles direcionadas, voltadas, principalmente, para a forma verticalizada como foram elaborados. Por outro lado, outras tantas se referiam à indefinição teórico-metodológica do documento (CAMACHO e ALMEIDA, 2008). Embora não tenham caráter de obrigatoriedade, os PCN representam, ainda hoje, importantes referenciais para a prática pedagógica, inclusive porque um dos critérios para aprovação no Programa Nacional do Livro Didático (PNLD) é a adequação dos conteúdos em relação aos PCN. Neste sentido, considerando seus avanços, limitações e possibilidades, ainda faz-se necessário discuti-los. Portanto, será analisado neste artigo de que forma a geografia política e também a escala local são abordadas no documento em questão. Antes disso, porém, traremos alguns elementos relevantes para a análise a respeito dos estudos das dinâmicas locais na geografia política atual.

Tendo como base de análise central as relações entre política e território, nos dissensos e consensos presentes nestas relações e nos rebatimentos destes processos sociais no e partir do território, a geografia política vem se revigorando gradativamente, sobretudo a partir dos anos de 1970 no contexto de renovação da geografia como um todo. Desde então muitos livros vem sendo publicados com concepções e temas variados, inclusive enfatizando a escala local. Esta se apresenta como uma importante ferramenta conceitual não somente para ampliar a compreensão da complexidade do território, também em sua dimensão multiescalar, mas, sobretudo, para ser mais uma lente de visualização e análise do mundo atual globalizado. Tomando como referência a concepção de Castro, na qual escala significa uma "medida que confere visibilidade ao fenômeno" (1995, p. 123), compreendemos que cada escala reflete a escolha do que, intencionalmente, ficará visível em determinado fenômeno - no caso deste estudo a cidadania no ensino da geografia política local. Essa concepção pressupõe a não hierarquização das escalas, na medida em que sua escolha não reduz nenhum fenômeno. Trata-se, portanto, de aplicar o conceito de escala para visibilizar um determinado aspecto da geografia política, a cidadania.

Os primeiros estudos locais que surgiram neste período de renovação da geografia e da geografia política, em particular, eram de caráter urbano, empíricos e se fundamentavam nos conflitos de localização (TAYLOR,1985). A partir daí vários outros temas e métodos foram se inserindo na agenda desta disciplina. Com base em Fonseca (2003), pelos menos cinco principais temáticas locais passaram a ser investigadas pela geografia política, segundo levantamento realizado nas revistas Political Geography, Political Geography Quarterly, Progress in Human Geography, e se baseando nas contribuições da literatura geográfica, espanhola e brasileira. As temáticas são as seguintes: conflitos de localização; processos eleitorais; estrutura administrativa do Estado; relações entre o governo central e o governo local; e as relações entre o global e o local.

Dentro destas temáticas mais gerais, vem sendo desenvolvidas variadas pesquisas em torno da geografia política local enfatizando os novos modelos de gestão do território; iniciativas locais de combate ao desemprego; estratégias de atração de empresas e competição entre os lugares; organização e mobilização da sociedade em torno de questões ambientais, educacionais, culturais; criação e atuação de conselhos; ampliação de consórcios intermunicipais; criação de agenda 21 local; criação de novos planos diretores; divisão/ criação de novos municípios; e conflitos entre municípios. São processos que tem emergido com maior expressão desde o final do século XX, denominados de localismos por Fonseca (2013).

Apesar de todo este processo de renovação e sem perder de vista que "é na relação entre a política - expressão e modo de controle dos conflitos sociais - e o território base material e simbólica da sociedade - que se encontram os temas e questões do campo da geografia política" (CASTRO, 2005, p. 41), a ausência de temáticas mais vinculadas diretamente ao ensino nos leva à seguinte questão: a geografia política é importante enquanto saber escolar? Qual sua contribuição na formação do aluno?

Embora praticamente não ocorra nos $\mathrm{PCN}$ referência à expressão geografia política, suas temáticas são observadas 
permeando diferentes trechos do documento. É necessário que se compreenda, portanto, que determinados conteúdos podem ser aí enquadrados sem, necessariamente, aparecerem sob este rótulo nos livros didáticos ou nos PCNs. E, embora sejam inúmeras as críticas de caráter teórico-metodológico acerca dos parâmetros, em diferentes trechos é sinalizada a necessidade de abordagens multiescalares.

Ao propor um enfoque não hierárquico os $\mathrm{PCN}$ indicam uma negação à metodologia dos círculos concêntricos, pois preconiza que as escalas sejam trabalhadas de modo não linear, durante a trajetória escolar do aluno. Os PCN se desenvolveram numa linha teórico-metodológica 'eclética', mas com predominância da perspectiva fenomenológica, vinculada, sobretudo, ao conceito de lugar que ganha papel central nas abordagens, principalmente no que se refere aos primeiros ciclos escolares. Ou seja, a valorização dos laços afetivos, experiencial e intencional com o espaço, explicitada na corrente cultural/humanista, foi à tônica para a abordagem da escala local nos PCN em detrimento da outra concepção de lugar, fundamentada na geografia crítica ou radical na qual a categoria é analisada como expressão de singularidade, foco de articulação entre o local e global (FONSECA, 2005).

No documento referente ao ensino médio, embora com um peso mais equilibrado em relação às outras categorias, o lugar continua a se expressar como dimensão da escala local, da vivência e da subjetividade e, também, ocorre a valorização de conteúdos técnicos e normativos (BRASIL, PCN de Geografia, 2000). Mesmo assim, não é somente através destas concepções, necessariamente, que a dimensão política do local seria mais evidenciada.

De forma geral, o que se observa nos PCN é a supervalorização do aspecto cultural em detrimento do político e econômico. Como foi dito, são nos primeiros ciclos que o aspecto cultural ganha maior espaço no currículo escolar, o que nos vai permitindo questionar até que ponto foi superada a lógica linear das escalas. Há, no nosso entendimento, certa continuidade na lógica escalar hierárquica, mas também há uma gradativa politização dos conteúdos, na medida em que os ciclos escolares avançam. Quando a escala local é substituída gradativamente por outras, a dimensão política do espaço vai ganhando também maior relevo nos eixos temáticos propostos pelos $\mathrm{PCN}$ e a categoria território passa, também gradativamente, a compor as abordagens de forma mais significativa. A primeira referência ao conceito de território aparece inserida nos ciclos iniciais do Ensino Fundamental, enquanto "conjunto de paisagens contido pelos limites políticos e administrativos de uma cidade, estado ou país. É algo criado pelos homens, é uma instituição". (BRASIL, PCN de História e Geografia, 1998, p. 75). Esta já é uma concepção que remete diretamente a um território politizado e, mais ain- da, um território institucionalizado. A concepção apresentada também não se restringe à ideia de território nacional e de Estado-Nação, já que cita a cidade, o Estado e o país. Mas, de uma forma geral, os PCN dos anos inicias ainda não depositam significativa valorização à categoria território, posto que durante os primeiros ciclos ela não é desenvolvida de maneira mais aprofundada. No documento dos anos finais do ensino fundamental é dada maior relevância a algumas problematizações da geografia política, através de um dos eixos temáticos propostos, denominado "A geografia como uma possibilidade de leitura e compreensão do mundo" (BRASIL, PCN de História e Geografia, 1998, p. 56). Este eixo abre espaço para discussões sobre os conflitos políticos que são veiculados pela mídia e sugere que seja estimulado um debate acerca destas temáticas. Entretanto, novamente predomina o olhar para a escala nacional e global, em detrimento de outras dimensões escalares, inclusive local.

Ainda neste eixo temático uma questão relevante é colocada, através da sugestão do tema denominado 'a conquista do lugar como conquista da cidadania' (BRASIL, PCN de História e Geografia, 1998, p. 59). Neste tema é sugerido ampliar as discussões acerca do significado da cidadania, discutindo o conceito em consonância com algumas de suas expressões cotidianas, tais como transporte e moradia. Aí emerge a possibilidade de trabalhar, mais amplamente, de que maneira estas expressões são reflexo do conflito e/ou conciliação de interesses políticos de diferentes agentes sociais, com maior aproximação entre a escala local e a expressão política do território, relação esta pouco valorizada nos PCN. Outro eixo temático que, de certa forma, incorpora algumas problematizações da geografia política é aquele denominado "O campo e a cidade como formações sócio-espaciais" que objetiva estimular no aluno os questionamentos acerca do poder político e do Estado. Neste eixo é discutida pela primeira vez, de forma mais aprofundada, a ação do Estado e seus rebatimentos no território.

Esta ampliação do enfoque político a partir da transição entre o Ensino Fundamental e o Médio é justificada nos PCN através do entendimento de que os alunos, nesta etapa escolar, ampliam seus interesses e curiosidades pelos assuntos veiculados na mídia e tem maior predisposição à politização. Também se complexifica o olhar para a vida cotidiana que, para além dos vínculos afetivos e de pertencimento, explicita também os interesses e conflitos políticos em jogo e a atuação do Estado no território. Nos PCN do Ensino Médio a politização dos fenômenos geográficos é aprofundada e há uma considerável retomada da escala local no sentido da construção da cidadania, embora ainda relacionada somente à subjetividade do lugar.

Embora ainda através da categoria 'lugar', a escala lo- 
cal já passa a expressar nos PCN do ensino médio sua dimensão política com maior relevo, a partir da constatação dos consensos e conflitos que possuem expressão direta no cotidiano. Também ‘território' é retomado, com destaque para uma construção conceitual mais complexa do que aquelas até então realizadas nos ciclos anteriores: "Todo território, seja ele um quarteirão na cidade de Nova York, seja uma aldeia indígena na Amazônia, é definido e delimitado segundo as relações de poder, domínio e apropriação que nele se instalam” (BRASIL, PCN de Geografia, 2000, p.33).

$\mathrm{A}$ análise dos três documentos referentes aos PCN evidencia dois problemas teórico-metodológicos principais, relativos aos conteúdos da geografia política e a escala local ao longo dos diferentes ciclos escolares. O primeiro deles é a permanência do entendimento linear das escalas geográficas. Embora propague justamente a superação desta lógica, os PCN dão continuidade à uma abordagem fragmentada e que apenas nos últimos ciclos evidencia a complexidade da escala local e da vida cotidiana. O segundo problema refere-se à dificuldade em considerar a abordagem política do espaço geográfico em escalas diferentes da nacional e global.

Se estes problemas se encontram latentes no texto dos PCN, também podem ser ainda mais evidenciadas a partir da estruturação dos conteúdos nos livros didáticos e na abordagem destes nas escolas. $E$ no intuito de observar como estas proposições lançadas pelos PCN chegam às salas de aula, serão analisadas, no próximo item, quais as principais abordagens relativas à geografia política e como estão sendo desenvolvidas pelos professores que lecionam na educação básica em colégios estaduais de Salvador-BA.

\section{A GEOGRAFIA POLÍTICA EM SALA DE AULA EM COLÉGIOS ESTADUAIS DE SALVA- DOR-BAHIA}

Para identificar as abordagens e as práticas dos professores em sala de aula, foram realizados trabalhos de campo em 16 colégios estaduais de Salvador e foram aplicados questionários a 23 professores. O questionário constou de duas questões. A primeira delas solicitava aos professores que enumerassem, por ordem de importância, os temas da geografia política abordados em sala de aula a partir de uma lista contendo 13 itens, envolvendo temas que encontram-se com maior frequência em livros didáticos, juntamente com outros temas que julgamos necessários para o ensino, como movimentos sociais, democracia e gestão territorial na escala do Município. A partir da tabulação das respostas obtidas foi calculada a ordem de importância de cada tema listado, na qual quanto mais próxima da média 1 mais importante, quanto mais distante da média 1 , menos importante.
Conforme a tabela 1 , os cinco temas que ganharam maior importância nas abordagens dos professores entrevistados foram àqueles relativos à escala nacional - relacionando-se com a ideia de Estado-Nação e da organização do território nacional - bem como aqueles relativos à escala global e supranacional, como globalização e nova ordem mundial e organizações internacionais e blocos econômicos. Vale observar, também, que temas como "conflitos e guerras na escala global" e "redefinição de fronteiras", que possuem um forte vínculo com a escala global e dialogam diretamente com a dimensão política, foram considerados menos importantes que os demais.

Quanto aos os cinco temas considerados menos importantes, três deles são justamente aqueles inseridos pelo critério da nossa escolha pessoal, já que praticamente não aparecem inseridos em livros didáticos (temas 9, 12 e 13). Neste sentido, observa-se que mesmo sendo temas que possibilitam reflexões importantes acerca do poder e do território, não costumam ser abordados em sala de aula ou são tidos como de pouca relevância em relação aos outros. Percebe-se também, que o tema gestão territorial do município, além de ter a menor importância média entre os temas (TABELA 1), também não é abordado em sala de aula por $24 \%$ dos professores que responderam ao questionário, conforme a tabela 2. Além deste, outros temas como redefinição de fronteiras, democracia e poder político regional e local também são pouco abordados. Ou seja, a escala local juntamente com temas vinculados como poder local, gestão local e democracia ainda são pouco discutidos nas aulas de geografia, o que vai repercutir diretamente no desenvolvimento da consciência política dos estudantes.

Tabela 1 - Principais temas da geografia política abordados em colégios estaduais de Salvador/Bahia conforme a opinião de professores e segundo a ordem média de importância - 2014

\begin{tabular}{|c|c|c|}
\hline & TEMA & $\begin{array}{l}\text { ORDEM DE } \\
\text { IMPORTÁNCIA } \\
\text { (MÉDIA) }\end{array}$ \\
\hline 1 & Formaçåo territorial dos Estados Nacionais & 4.65 \\
\hline 2 & Globalizaçâo e nova ordem mundial & 4,74 \\
\hline 3 & Organizaçâo do Estado e território nacional & 4,91 \\
\hline 4 & $\begin{array}{l}\text { A sociedade e as diferentes formas de organizaçăo politica } \\
\text { e gestăo do território }\end{array}$ & 5,57 \\
\hline 5 & Organizaçôes internacionais e blocos econômicos & 5,87 \\
\hline 6 & Democracia e cidadania: a reivindicaçăo dos direitos & 6.74 \\
\hline 7 & Poder politico nas escalas regional e local & 7,48 \\
\hline 8 & Geopolitica dos recursos naturais & 7,65 \\
\hline 9 & Movimentos sociais e suas aç̋̄es territoriais & 8.48 \\
\hline 10 & Confitos e guerras na escala global & 8,52 \\
\hline 11 & Redefiniçâo de fronteiras & 8,87 \\
\hline 12 & Para além do Estado: democracia direta e auto-governo & 9.35 \\
\hline 13 & A gestāo territorial do municipio & 10,26 \\
\hline
\end{tabular}

Elaboração: Lara Moraes, 2014

Consideramos a escala local fundamental nas abordagens da educação básica, por dois aspectos principais: o primeiro refere-se ao fato de que para alcançar a aprendizagem significativa é necessário partir dos conhecimentos pré- 
vios do aluno (AUSUBEL; NOVAK; HANESIAN, 1980), (FREIRE, 2011); e o segundo refere-se ao potencial existente na escala local para a efetivação da cidadania (VAINER, 2001). Isso por que é nela em que ocorre a vivência no mundo, em que os direitos (saúde, educação, transporte, moradia, trabalho, etc.) podem ser espacializados de maneira mais próxima e visível, atendidos e reivindicados e é nela também que a correlação de forças e as relações de poder se expressam mais próximas ao aluno, influenciando diversos aspectos do seu cotidiano..

Tabela 2 - Temas da Geografia Política não abordados em sala de aula, segundo professores entrevistados 2014

\begin{tabular}{|c|c|}
\hline TEMA & $\begin{array}{l}\text { ENTREVISTADOS QUE NÅO ABORDAM O } \\
\text { TEMA (EM \%) }\end{array}$ \\
\hline Gestāo territorial do municipio & 24,0 \\
\hline Redefiniçáo de fronteiras & 16,0 \\
\hline $\begin{array}{l}\text { Para além do Estado: democracia direta e } \\
\text { autogoverno }\end{array}$ & 12,0 \\
\hline Poder politico nas escalas regional e local & 12,0 \\
\hline Formaçâo territorial dos Estados Nacionais & 8,0 \\
\hline Movimentos sociais e suas aç̄ōes territoriais & \\
\hline $\begin{array}{l}\text { Democracia e cidadania: a reivindicaçắo dos } \\
\text { direitos }\end{array}$ & 8,0 \\
\hline Geopolitica dos recursos naturais & \\
\hline $\begin{array}{l}\text { Organizaçōes internacionais e blocos } \\
\text { econômicos }\end{array}$ & 4,0 \\
\hline
\end{tabular}

Elaboração: Lara Moraes, 2014.

Nota 1: O somatório não fecha em 23 porque foram citados mais de um tema por entrevistado

Partimos, portanto, de premissas que relacionam diretamente a escala local com a cidadania e a aprendizagem significativa. Neste sentido, os resultados encontrados a partir da pesquisa nos fazem questionar até que ponto estes objetivos estão sendo buscados e alcançados no ensino básico. Observa-se que até mesmo o tema que carrega explicitamente esta ideia, democracia e cidadania: a reivindicação de direitos, não figura entre aqueles considerados mais importantes. Se por um lado os resultados encontrados, observando as tabelas 1 e 2, demonstram seguir um caminho oposto ao que é defendido neste artigo, por outro, corroboram com a análise dos PCN realizada na seção anterior, que apontou a predominância de abordagens políticas apenas nas escalas nacional e global. Categorias tais como Estado, território e poder são trabalhadas, em geral, a partir destas duas escalas e, ainda assim, apresentando conceitos simplificados e pouco abrangentes.

No segundo item do questionário foi solicitado aos entrevistados que respondessem sobre qual a importância de se abordar temas relacionados à geografia política nas salas de aula da educação básica e quais sugestões poderiam ser dadas para tornar este conteúdo mais atrativo e útil aos alunos. Por tratar-se de uma questão aberta e subjetiva a separamos em três aspectos, no momento da tabulação: (i) importância da geografia política; (ii) abordagem escalar citada, se houver; (iii) sugestões para tornar o conteúdo mais atrativo e útil para o aluno. Neste caso, 23 entrevistados responderam a pergunta e os resultados obtidos para o primeiro aspecto (i) apontaram o seguinte: $52 \%$ consideraram que a geografia política é importante para a formação cidadã e crítica; $22 \%$ não responderam; $13 \%$ disseram que a geografia política ajuda na ampliação dos conhecimentos; $13 \%$ informaram que é importante para a compreensão da geopolítica atual.

Em relação ao aspecto (ii) relativo à abordagem escalar citada pelos professores no decorrer de sua resposta, a maior parte dos que responderam, $52 \%$, não citou nenhuma escala, $13 \%$ citaram a escala global, $13 \%$ a nacional e global conjuntamente, $13 \%$ citaram uma visão multiescalar e 8,7\% citaram apenas a escala nacional. Nestas respostas, nenhum professor fez referência direta às escalas local e a regional.

E no que se refere ao aspecto (iii), relativo às sugestões dadas para tornar o conteúdo em questão mais atrativo e útil para os alunos, os resultados foram sistematizados na tabela 3 e indicam que $24 \%$ acreditam que um dos caminhos possíveis é realizar uma abordagem mais contextualizada, aproveitando os conhecimentos prévios que os alunos apresentam e realizando um maior diálogo entre as escalas geográficas. Estas colocações merecem ser destacadas por estabelecerem uma relação tão cara aos debates pedagógicos, relacionadas às teorias da aprendizagem e apontarem para uma relação mais horizontal entre professor-aluno.

Quanto às outras sugestões destaca-se, também com $24 \%$, a utilização das tecnologias da informação e comunicação (TIC) que foram exemplificadas enquanto multimídias, no intuito de tornar as aulas mais atrativas e dinâmicas, dado o momento atual de grande apelo tecnológico, principalmente relacionado aos adolescentes.

Tabela 3 - Sugestões para tornar o conteúdo mais atrativo e útil para o aluno, segundo professores entrevistados - 2014

\begin{tabular}{lr}
\hline SǓGESTÓES & $(\%)$ \\
\hline Atençăo aos conhecimentos prévios do aluno e diálogo entre & 24,1 \\
as escalas & 24,1 \\
Uso das TIC & 13,8 \\
Estimular maior participação do aluno & 6,7 \\
Interdisciplinaridade & 6,7 \\
Aula com atualidades geopoliticas & 6,7 \\
Outros & 17,2 \\
Não responderam & \\
\hline
\end{tabular}

Elaboração: Lara Moraes, 2014.

Nota 1: TIC: Tecnologias da Informação e Comunicação.

Nota 2: O somatório das sugestões dadas não fecha em 23 entrevistados porque foram dadas mais de uma sugestão por entrevistado

Acreditamos que com a realização desta etapa da pesquisa, através da aplicação dos questionários e da posterior tabulação, foi possível mapearmos, ainda que de forma exploratória, quais abordagens predominam quando o conteúdo é geografia política. Foi possível observar inclusive que, para além dos conteúdos conceituais, muitos professores mencionaram a importância da geografia política para a construção de conteúdos atitudinais relativos ao exercício da cidadania e da democracia. E com base nos resultados obtidos e nas 
análises realizadas, será apresentada a seguir uma abordagem propositiva da geografia política local que poderá ser aplicada e desenvolvida em sala de aula. Nesta abordagem, a escala local, representada pelo município, assume um papel central, tendo em vista que tem a capacidade de potencializar a aprendizagem significativa e a efetivação da cidadania.

\section{O ENSINO DO LOCAL COMO INSTRU- MENTO PARA A CONSTRUÇÃO DA CIDADA- NIA}

Cabe agora delimitar em quais termos a transposição dos conteúdos da geografia política pode ocorrer através da escala local para alcançar, de fato, uma aprendizagem significativa e que leve ao alcance da cidadania.

Desde a Grécia antiga até os dias atuais, a cidadania vem apresentando variados significados. $O$ termo atingiu seus contornos mais definidos e contemporâneos através de Marshall, em 1949, que estabeleceu três elementos ou dimensões fundamentais da cidadania: os direitos civis, sociais e políticos (MARSHALL, 1967). Estes três elementos, conforme o autor, só se concretizam concomitantemente, consolidando o que poderia ser chamado de cidadania plena. Importante salientar que esta formulação guia até hoje diversos países e suas constituições oficiais, inclusive a Constituição Federal brasileira de 1988, também conhecida enquanto constituição cidadã.

Nas últimas décadas outros conteúdos foram incorporados e a cidadania adquiriu um significado além da simples relação de direitos e deveres. Sobre este aspecto Covre (2013) nos alerta para o fato de que esta noção de cidadania que tem sido aceita ao longo das últimas décadas carrega consigo um potencial desmobilizante dos setores subalternizados, através de um atendimento corporativista dos direitos instituídos, no intuito de mantê-los continuadamente sob controle. Este aspecto de controle dos anseios de liberdade, como também a tentativa de confundir a noção de cidadania com a de consumo, nos alertam para a importância de acompanhar criticamente os avanços em torno do conceito de cidadania para que compreendamos quais suas potencialidades e suas limitações e quais são as intencionalidades embutidas em determinados usos.

No Brasil houve, a partir da década de 1980, com o processo de redemocratização, alterações significativas em relação ao arranjo político do país, caminhando para o federalismo tripartite e culminando em uma Constituição Federal que preconizava maior descentralização e maior participação popular nos processos decisórios. Embora saibamos que estes mecanismos de rótulo participativo e descentralizador possam significar apenas mais uma forma de escamotear os conflitos de interesses e de refrear o avanço de novas reivin- dicações, eles podem representar, por outro lado, um aceno importante para o aprofundamento de determinados avanços na cidadania. Esta é entendida aqui como uma iniciativa que emerge do povo, através de seu poder de reivindicação para construção de seus próprios direitos e deveres frente ao Estado. Conforme Santos (1998) e Covre (2013), não se trata, portanto, de uma cidadania passiva, mas de uma estratégia de luta. Embora certamente passe pela noção de cidadania participativa, a cidadania efetiva ou plena na qual acreditamos vai além, à medida que os cidadãos se tornem, de fato, vOz ativa nas decisões da vida política. E no intuito de compreender melhor as relações estabelecidas entre o exercício da cidadania e sua expressão territorial, será dada ênfase, a seguir, ao município, enquanto importante instância do poder político institucionalizado, enquanto lócus do cotidiano social e, portanto, enquanto importante categoria operacionalizante da educação para a cidadania, especificamente no Brasil.

Como pontuado por Covre (2013), o exercício da cidadania exige condições democráticas mínimas que permitam sua realização, entre elas uma Constituição que assegure o poder de voz ativa dos cidadãos e, consequentemente, seu poder de reivindicação. A Constituição brasileira de 1988, ao estabelecer um rearranjo no pacto federativo brasileiro, passou a considerar o município como um ente federado ao lado da União e dos estados, instituindo um federalismo tripartite. A importância do município gerado neste novo arranjo significou um passo importante ao dar o devido destaque a uma escala de ação política fundamental e presente desde o período colonial brasileiro (FONSECA, 2005).

A maior capacidade de decisão, execução e ação de políticas adquiridas pelos municípios brasileiros veio acompanhada de mais responsabilidades para os governos locais e, ao mesmo tempo, abriu brechas para ampliar o espaço das reivindicações sociais, tanto por preconizar um maior nível de participação popular nas instâncias políticas decisórias, como por descentralizar a gestão política local. E no caso brasileiro, é importante salientar que é na e através desta escala político-administrativa que a cidadania poderá se concretizar de maneira mais clara, sem perder de vista que a análise dos processos e relações sociais deve ser realizada estabelecendo um diálogo incessante entre as diferentes escalas, de maneira transescalar, conforme nos lembra Vainer (2001). Neste caso, a escala local (e, portanto, o município) aparece com maior potencialidade para a criação de uma cidadania verdadeiramente plena porque é nela onde o processo de socialização histórico e as relações sociais acontecem de forma mais evidente tendo em vista a importância da proximidade geográfica.

Mas, a compreensão da cidadania se faz a partir de um diálogo incessante entre as escalas e que, de fato, perpassa por 
diversas delas através da transescalaridade. Isso é fundamental para que não caiamos no reducionismo e no paroquialismo local, estudando o município por ele mesmo. O desafio está justamente em compreender o local inserido dentro do contexto espacial, econômico, social, político e institucional do qual faz parte. E dentro desta perspectiva, o município não é apenas a dimensão da vivência (lugar, espaço vivido), mas também lócus da produção e reprodução de relações de poder, interesses e embates políticos, representatividade política, expressão local do Estado no território e com capacidade de gerar normas de regulação, uso e ocupação do território. Essa abordagem tem a vantagem de diminuir a predominância exagerada de enfoques culturais ou econômicos, como tem sido de costume, bem como abordagens que valorizam apenas as escalas nacional e supra-nacional para explicar os processos locais. Ao colocarmos essa especificidade do município no federalismo brasileiro enquanto objeto de estudo da educação básica, estamos permitindo que o aluno amplie sua compreensão política sobre a realidade social em que está inserido. Mais do que isso, é a partir desta realidade que o aluno pode alcançar noções mais universais da geografia política, como aquelas relativas ao Estado e a gestão territorial.

Proposições referentes ao estudo do município no ensino de geografia já foram apresentadas por Callai e Zarth (1988), como a utilização da sistemática "Registro - Produção - Análise" enquanto etapas não lineares do estudo, estando em constante retroalimentação e se utilizando de diferentes procedimentos metodológicos. Nesta direção, será apresentada a seguir uma proposta de sequência didática para o ensino do local. Sabendo da natureza dinâmica e complexa da sala de aula não pretendemos neste trabalho elaborar um receituário ou um passo-a-passo fechado, mas sim indicar caminhos que poderão facilitar a inserção da temática na sala de aula.

\subsection{Sequência Didática: o município e sua dimen- são política}

Objetivos: compreender como a política se expressa no território do seu município, seja através da distribuição dos serviços públicos e do atendimento de direitos sociais, seja a partir dos atores sociais que estabelecem uma correlação de forças local, tais como movimentos sociais, sociedade civil e poder instituído. Associado a isto, pretende-se que os alunos se compreendam enquanto agentes ativos e políticos na construção deste território.

Conteúdos: gestão territorial do município, organização do Estado no território nacional (federalismo brasileiro), de- mocracia e atendimento e reivindicação de direitos.

$$
\text { Séries: Ciclos finais do Ensino Fundamental e Ensino }
$$
Médio.

$1^{a}$ etapa: o professor deve apresentar uma situação-problema que se relacione com a vida política e a gestão territorial no município em questão. Outra opção para esta primeira etapa é que o professor solicite aos alunos que pensem e discutam sobre a distribuição de serviços públicos no território do Município, por exemplo: distribuição de escolas, postos de saúde, postos policiais, transporte público, conjuntos habitacionais, situação do esgotamento sanitário, calçadas, espaços públicos, iluminação pública, etc. A ideia é que os alunos reflitam sobre como a gestão do Município reflete no seu cotidiano e como os serviços estão distribuídos espacialmente;

$2^{a}$ etapa: com a ajuda do professor, os alunos deverão propor questões que tentem explicar quais as causas que levaram a uma determinada organização e gestão territorial no município discutida na etapa anterior e também quais as conseqüências desta organização territorial. Embora as questões devam surgir a partir de cada situação e relação professor-aluno, algumas delas podem se relacionar com os questionamentos colocados a seguir: o Estado brasileiro está organizado através de uma estrutura federalista tripartite: quais responsabilidades são geradas para cada ente federado (União, Estados e Municípios)? Existem bairros no município em que os serviços públicos são melhor ofertados? Quais os principais agentes políticos do município (tanto no que se refere ao poder instituído, quanto àqueles que emergem da mobilização popular)? No que se refere à prefeitura e câmara de vereadores, qual o perfil político e ideológico dos seus representantes? Quais deles possuem maior voz nestes espaços? Quais são as principais pautas dos movimentos sociais atuantes no município? Qual a relação estabelecida entre estes diferentes agentes e seus interesses? Existem no município instâncias políticas de participação popular, como Conselhos? Como atuam? De que forma a sociedade organizada poderia intervir na gestão do município?

$3^{a}$ etapa: após sistematizarem as principais questões a serem respondidas ao longo do estudo deverá se estabelecer quais fontes de pesquisa serão utilizadas e dar seguimento a elas. Nesta etapa os alunos desenvolverão habilidades importantes relativas à coleta de informações e dados, estabelecendo um enfoque em conteúdos procedimentais. Além da coleta de dados secundários, os alunos poderão utilizar instrumentos como fotografias, entrevistas e questionários para 
obterem dados primários e que, certamente, darão ainda mais credibilidade e significado ao estudo. Nesta etapa ainda é possível estimular os alunos a confeccionarem plantas ou croquis de algumas áreas da cidade que possam auxiliar na resposta aos questionamentos iniciais, fazendo que os conteúdos procedimentais relacionados à cartografia também sejam trabalhados. Algumas fontes possíveis para a coleta destas informações e dados podem ser mídia (jornais, revistas, canais locais de TV, rádio, sites); prefeitura, câmara de vereadores e secretarias; associação de moradores de bairro / lideranças comunitárias/movimentos sociais; e órgãos públicos que disponibilizem índices e estatísticas, como IBGE;

$4^{a}$ etapa: a partir dos dados e informações coletados os alunos deverão partir para a interpretação e formular conclusões a partir de tudo que foi visto ao longo do processo. Nesta etapa o objetivo principal é observar se as questões colocadas durante a $2^{\mathrm{a}}$ etapa foram respondidas satisfatoriamente $\mathrm{e}$ elaborar a partir delas uma discussão sobre a vida política no município, distinguindo quais são os principais problemas, os desafios e as possibilidades de atuação para melhorar a vida local. Esta etapa resultará num relatório de campo, composto pelos questionamentos iniciais, pela compilação dos dados e informações coletados e pela interpretação realizada;

$5^{a}$ etapa: nesta etapa, mais expositiva do que as demais, pretende-se fazer com que - das situações-problema e da prática cotidiana dos alunos, alvo das etapas anteriores - o professor possa apresentar a definição dos conceitos envolvidos, tais como Estado, território, gestão e democracia, dando ênfase ao papel do Município enquanto escala do poder local e da vida política cotidiana: “O município é o espaço em que o povo vive, não o Estado ou a nação, e, no espaço local desdobra-se o cotidiano de dupla face, de participação ou de exclusão.” (SOARES, 2006, p. 78). Essa abordagem abre um grande leque de questões a serem discutidas, tais como gestão territorial, distribuição de serviços públicos, descentralização, administração dos interesses, por vezes conflitantes, entre sede, distritos e povoados. Nesta etapa faz-se essencial também tratar sobre a diferenciação entre os termos Município e Cidade, que são comumente colocados enquanto sinônimos no ambiente escolar. Essa diferenciação está diretamente relacionada a diversidade espacial existente na realidade do Município, abrangendo uma área urbana enquanto sede, a qual chamamos de cidade, e áreas rurais, abrangendo vilas e povoados que, por vezes, são negligenciados pelo poder local. É desta relação que nascem as disputas por emancipação política de distritos e a formação de novos municípios no Estado brasileiro, conteúdo este de grande relevância e desdobramentos para o estudo da geografia política local, na educação básica. $\sigma^{a}$ etapa: com base nos questionamentos iniciais, na pesquisa e na análise realizada os alunos deverão produzir materiais que possibilitem um contato continuado com as temáticas estudadas. O esperado é que os materiais produzidos possam ser utilizados também em outros momentos. $\mathrm{Na}$ sequência, apresentamos algumas sugestões:

- Mural sobre a vida política do município: ao elaborar este material, que ficaria disponível na escola, os alunos terão a possibilidade de alimentá-lo ao longo do ano, com notícias, curiosidades e projetos que se relacionem com os agentes políticos locais, a oferta de serviços públicos, a reivindicação de direitos, etc. Este material possibilita que toda a comunidade escolar tenha conhecimento que foi produzido ao longo deste processo, além de estimular as discussões políticas;

- Exposição de fotos e/ou vídeos: ao longo da etapa de pesquisa e coleta de informações e dados espera-se que os alunos também utilizem como instrumento recursos áudio-visuais, o que possibilita que, ao final do processo, seja realizada uma exposição de fotos e vídeos que revele à comunidade escolar os caminhos percorridos pelos alunos ao longo do estudo, explicitando também as impressões obtidas acerca da organização territorial do município e da expressão dos conflitos políticos existentes;

- Debates: a realização de debates sobre algumas das situações-problema identificadas pode representar um mecanismo para estreitar os laços da comunidade escolar com a população do entorno e inclusive de outras áreas da cidade. Os debates abertos à comunidade podem contar ainda com convidados, estudiosos das temáticas relacionadas, representantes políticos e membros de movimentos sociais, que teriam como principal objetivo ampliar a percepção dos problemas discutidos, a partir de diferentes pontos de vista, e pensar conjuntamente quais os desafios e possibilidades existentes de intervenção;

$7^{a}$ etapa: a partir da observação de todas as etapas anteriores e do desenvolvimento dos alunos relacionado aos conteúdos conceituais, procedimentais e atitudinais, bem como através da análise do relatório de campo apresentado, o professor avaliará processualmente a aprendizagem realizada.

A elaboração desta sequência didática representa uma tentativa de ampliar os horizontes de uma aprendizagem significativa voltada para a dimensão política da vida local. Neste sentido, nos aproximamos da concepção de aprendizagem vygotskyana, entendendo-a como um processo que ocorre sempre histórica e espacialmente situada e que, por isso, deve se conectar com a realidade socioespacial dos educandos. É neste sentido que propomos, antes de qualquer explanação 
teórico-conceitual, que os professores abram espaço para o diálogo, a partir do qual será possível identificar quais os conhecimentos prévios existentes e quais as possibilidades de atuação. Ao deixar em aberto algumas questões, como o tempo necessário para a sua realização e as séries a serem trabalhadas, pretendemos deixar claro que trata-se de uma proposta abrangente e genérica, que permite a sua utilização em diferentes formatos. A ideia é que a abordagem da vida local não se dê através de uma hierarquização das escalas, da qual já falamos anteriormente. Decorre daí, portanto, o fato de não haver necessariamente uma série ou ciclo de ensino mais adequado, devendo haver adaptações para cada realidade escolar.

\section{CONSIDERAÇÕES FINAIS}

As análises realizadas ao longo deste trabalho nos fizeram assumir a premissa de que uma aprendizagem de fato comprometida com o educando deve partir, essencialmente, da realidade local - o que entrelaça estas questões com a abordagem escalar tão cara a geografia. Esta relação, na verdade, também embasou outra premissa adotada neste trabalho: a de que, ao colocarmos a geografia política enquanto conteúdo relevante para o contexto escolar, principalmente objetivando o alcance da cidadania, e levando em conta os aspectos já colocados sobre a aprendizagem significativa, a escala local se faz ainda mais potencializadora, porque é nela em que a cidadania é exercida e pode, inclusive, ser reclamada. Outro aspecto revelado pela análise aqui empreendida refere-se ao conteúdo presente nos PCN que, de alguma forma, continuam a influenciar as abordagens em sala de aula. A análise demonstrou que tais parâmetros apresentam os conteúdos geográficos através de uma abordagem escalar hierarquizada e a politização dos conteúdos também é gradativa. Neste sentido, chegou-se à conclusão de que há um desencontro nos PCN da escala local e da dimensão política da geografia.

Para que pudéssemos aprofundar a análise até então realizada foi fundamental a aplicação de questionários aos professores de colégios estaduais da capital baiana, para mapearmos quais abordagens, de fato, são predominantes em sala de aula. Os resultados demonstraram que há correspondência naquilo que é encontrado nos PCN, porque foi atribuída maior importância às temáticas relacionadas à escala nacional e global, enquanto que a temática relacionada à gestão territorial do município foi aquela de menor importância atribuída, dentre diferentes temáticas. Foi possível observar que se encontra presente nas respostas também a compreensão de que, para tornar o conteúdo mais útil e atrativo aos educandos, é necessário buscar uma abordagem mais contextualizada com a realidade espacial cotidiana destes e rela- cionar com outras escalas. Neste sentido, para que se altere a lógica de ensino-aprendizagem, se busque e se alcance uma aprendizagem mais significativa, acreditamos ser necessário agir em diferentes frentes de atuação, tais como a própria formação de professores, elaboração e revisão dos materiais didáticos disponibilizados, reflexão acerca das gestões escolares e seus princípios pedagógicos, maior diálogo horizontal entre acadêmica e escola, bem como maior conexão da realidade escolar com o seu entorno, seu bairro e sua cidade. Todos estes fatores, certamente, ajudarão a encontrar caminhos possíveis para que os objetivos aqui entendidos como fundamentais da educação básica (efetivação da cidadania e aprendizagem significativa) sejam atingidos.

\section{REFERÊNCIAS}

AUSUBEL, D; NOVAK, J; HANESIAN, H. Psicologia educacional. 2. ed. Rio de Janeiro: Interamericana, 1980.

BRASIL. Ministério da Educação. Secretaria de Educação Média e Tecnológica. Parâmetros Curriculares Nacionais (Ensino Médio). Brasília: MEC, 2000.

. Secretaria de Educação Fundamental. Parâmetros Curriculares Nacionais: Geografia. Brasilia: MEC/SEF, 1998.

CALLAI, H. C; ZARTH, P. A. O estudo do município e o ensino de historia e geografia. Ijui: livraria UNIJUÍ Editora, 1988.

CAMACHO, R. S; ALMEIDA, R. A. Os Parâmetros Curriculares Nacionais (PCNs) do Ensino Fundamental em debate. Revista Formação, Presidente Prudente, v. 1, n.15, p. 36-60, 2008. Disponível em: http://revista.fct.unesp.br/ index.php/formacao/issue/view/70. Acesso em: 23 de março de 2015

CASTRO, I. O problema da escala. In: CASTRO, I.; GOMES, P. C. C.; CORREA, R. L. (Orgs.). Geografia: conceitos e temas. Rio de Janeiro: Bertrand Brasil, 1995. p. $117-140$.

Geografia e Política: território, escalas de ação e instituições. Rio de Janeiro: Bertrand Brasil, 2005.

COVRE, M. L. O que é cidadania. São Paulo: Brasiliense, 2013. 
CHEVALLARD, Y. La Transposición didactica: del saber sábio al saber enseñado. Buenos Aires: Aique editores, 1998.

FONSECA, A. A. M. Instituição e Desenvolvimento Territorial: o desempenho municipal após o processo de descentralização. Feira de Santana: Gráfica da Universidade Estadual de Feira de Santana, 2005.

A geografia política e a valorização das dinâmicas locais. Humanas, Feira de Santana, n. 4, p. 13 -37, jul./ dez, 2003.

Federalismo, descentralização e a emergência de localismos no Brasil. In: ; PERTILE, N.; CALDAS; A. S.; BRITO; C. (Orgs.). Estado, território e a dinâmica das fronteiras: reflexões e novos desafios. Salvador: JM Gráfica e Editora, 2013. p. 159-186.

FREIRE, P. Pedagogia da autonomia: saberes necessários à prática educativa. São Paulo: Paz e Terra, 2011.

KAERCHER, N. A. O gato comeu a geografia crítica? Alguns obstáculos a superar no ensino-aprendizagem de geografia. In: PONTUSCHKA, N. N.; OLIVEIRA, A.U. (Orgs.). Geografia em Perspectiva. São Paulo: Contexto, v. 1, 2002. p. 1-383.

MARSHALL T. H. Cidadania, classe social e status. Rio de Janeiro: Zahar Editores, 1967.

SANTOS, M. O espaço do cidadão. 4. ed. São Paulo: Nobel, 1998.

SOARES, B. R. Cidade e município: observações sobre o poder local. In: SILVA, J.B.; LIMA, L.C.; ELIAS, D. (Org.). Panorama da Geografia Brasileira. 1ed. São Paulo: Annablume editora, 2006, v. 1, p. 77-94.

TAYLOR, P. Political Geography: World-Economy, Nation-State and Locality. London: Longman, 1985.

VAINER, C. B. As escalas do poder e o poder das escalas: o que pode o poder local? In: IX ENCONTRO NACIONAL DA ANPUR, 2001, Rio de Janeiro. In: Anais do IX Encontro Nacional da ANPUR, 2001. Anais... Recife, 2001. v. 1. p. 140-151.

\section{Correspondência dos autores:}

\author{
Lara Moraes Borowski \\ e-mail: laramoraes.b@gmail.com \\ Antonio Angelo Martins da Fonseca \\ e-mail: antonio.fonseca@ufba.br
}

Artigo recebido em: 24/04/2016

Revisado pelo autor em: 05/03/2017

Aceito para publicação em: 16/05/2017 